\title{
Benefits and Risks of Cloud Computing in E-Government Tasks: A Systematic Review
}

\author{
Arief Assaf*, Ayub Wahab Iis Hamsir, and Miftah Muhammad \\ Smart City Islands Research Group Laboratory of Faculty of Engineering, Universitas Khairun, 97719, Ternate, Indonesia
}

\begin{abstract}
The utilities of Cloud Computing have an essential role in e-government affairs because they can reduce the cost of using information technology services and allow users to access services anytime and anywhere. The success factor of e-government requires leadership, significant funds and the ability to overcome the risks faced by governments. In several government agencies, such as Ministries or Local Governments in developing countries, cloud computing is still not widely adopted compared to other developed countries. In order to build cloud computing adoption, it is crucial to recognize that an essential and specific issue related to cloud computing is the potential and perceived security risks posed by the adoption of the technology. Cloud computing is an option that can provide e-government with lower infrastructure costs and less initial investment than traditional systems. Cloud computing in e-government offers excellent benefits, despite its many risks. Therefore, the main objective of this paper mainly focuses on analyzing the benefits and risks associated with cloud computing in e-government affairs. In this paper, researchers conducted a systematic review (SR) research method to identify the 12 benefits and 8 risks of cloud computing in e-government affairs. Then, these government organizations can benefit significantly from cloud computing.
\end{abstract}

Keyword: Benefits and Risk, E-Government, Cloud Computing, Systematic Review

\section{Introduction}

Over the last few age, we have seen the widespread adoption of e-government in many countries as it has many benefits for citizens, governments and various stakeholders. Citizens can access the information or knowledge they need, get satisfaction from public services and expand communication channels. It will increase productivity, grow the business economy, share global knowledge, and have automated business processes and communications for government organizations. Despite all these benefits for egovernment, there are many disadvantages to it [1]. Over the past few years, the implementation and research on cloud computing in the context of eGovernment has increased rapidly [2]. Recent updates, new computing models, cloud computing, have been adopted globally, including: public administration[3]. We can consider that e-government is one of the signs of technological development of a country's government, representing many characteristics and benefits. However, it has several challenges, such as operating costs of software, hardware, and server installation, which can hinder the process of getting egovernment up and running [4]. The cloud allows users to access services anytime and anywhere and only pay for what they use. Cloud computing delivers computing resources based on different technologies such as cluster computing, distributed systems, and web-based services. It has become an attractive opportunity for companies as it fulfils their IT and infrastructure [5]. Cloud computing enables the growth of cost-effective and scalable IT services that can improve government services [6]. Government organizations have turned to cloud-based services to reduce their total investment in IT infrastructure and resources (e.g. data centres) and take advantage of the various benefits of cloud computing technology [7].

The structure of this paper consist of Chapter 1 Introduction, Chapter 2 Conceptual Background, Chapter 3 Methods, Chapter 4 Result and Discussion and the last chapter is 5 Conclusion and Future Work.

\section{Theoretical Background}

This section consists of conceptual background: cloud computing definition, essential characteristics, service model and e-government.

\subsection{The Concept of Cloud Computing}

The National Institute of Standards and Technology (NIST) described the definition of cloud computing as a model for enabling ubiquitous, convenient, on-demand network access to a shared pool of configurable computing resources (e.g., networks, servers, storage, applications, and services) that can be rapidly provisioned and released with minimal management effort or service provider interaction [8]. Cloud

\footnotetext{
* Corresponding author: assaf.arief@unkhair.ac.id
} 
computing technology has a system that is very different from conventional ones. In conventional computing systems, most of the computing resources are owned by an organization and are usually located at the location of the organization, and the organization bears all costs of owning these resources, which may include investment, operation and maintenance costs. In contrast to the cloud computing system, the organization is not required to own most of the computing resources in the cloud computing system because these resources belong to the provider. The organization uses only the computing resources offered by the provider, which are accessible via the Internet. Since resources are paid for using a payper-use method, the organization does not have to bear the burden of all the infrastructure costs mentioned[3].

\subsubsection{The Cloud's Characteristics}

NIST describes cloud computing using five main characteristics [13]. Namely:

1. Self-service: Consumers can unilaterally provision computing capabilities, such as server time and network storage, as needed automatically without requiring human interaction with the service provider.

2. Broad network access: Capabilities are available over the network and accessed through standard mechanisms that promote use by heterogeneous thin or thick client platforms (e.g., mobile phones, tablets, laptops, and workstations).

3. Resource pooling: Provider computing is aggregated to serve multiple users using a multitenant model, with different physical and virtual resources assigned and dynamically moved according to user requests.

4. Rapid elasticity: Capabilities can be dynamically assigned and defined, in some cases automatically, to scale quickly in and out of demand. To consumers, the capabilities available for provision often seem limitless and can be customized in any amount at any time.

5. Measured service: Cloud computing systems automatically control and optimize resource usage by leveraging measurement capabilities at multiple levels of abstraction appropriate to the type of service (e.g., storage, processing, bandwidth, and active user accounts)

\subsubsection{The Cloud's Deployment Models}

There are four main types of cloud deployment models according to NIST: private cloud, community cloud, public cloud, and hybrid cloud [13].

1. Private cloud: The technology infrastructure is provided for specific use by a single organization consisting of many business units/organizations. It may be acquired, managed, and operated by the organization, third parties, or a combination of them off-premises.

2. Public cloud; The cloud infrastructure is provisioned for open use by the general public. It may be owned, managed, and operated by a business, academic, or government organization, or some combination of them. It exists on the premises of the cloud provider.

3. Community cloud: The cloud infrastructure is provisioned for exclusive use by a specific community of consumers from organizations that have shared concerns (e.g., mission, security requirements, policy, and compliance considerations). It may be owned, managed, and operated by one or more of the organizations in the community, a third party, or some combination of them, and it may exist on or off-premises.

4. Hybrid cloud: The cloud infrastructure is a composition of two or more distinct cloud infrastructures (private, community, or public) that remain unique entities but are bound together by standardized or proprietary technology that enables data and application portability (e.g., cloud bursting for load-balancing between clouds).

\subsubsection{The Cloud's Services}

The service model of cloud computing services is divided into three parts [13]. There are details below:

1. Platform as a Service (PaaS): The capability provided to consumers is to deploy to the cloud infrastructure consumer-generated or acquired applications built using the programming languages, libraries, services and tools supported by the provider. The consumer does not manage or control the underlying cloud infrastructure, including network, servers, operating systems, or storage, but has control over deployed applications and possibly configuration settings for the application-hosting environment.

2. Software as a Service (SaaS): The capability provided to the consumer is to use the provider's applications running on a cloud infrastructure. The applications are accessible from various client devices through either a thin client interface, such as a web browser (e.g., web-based email), or a program interface. The consumer does not manage or control the underlying cloud infrastructure, including network, servers, operating systems, storage, or even individual application capabilities, with the possible exception of limited user-specific application configuration settings.

3. Infrastructure as a Service (IaaS): The capability provided to the consumer is to provision processing, storage, networks, and other fundamental computing resources where the consumer is able to deploy and run arbitrary software, which can include operating systems and applications. The consumer does not manage or control the underlying cloud infrastructure but has control over operating systems, storage, and deployed applications; and possibly limited control of select networking components (e.g., host firewalls). 


\subsection{E-Government Concept}

The adoption of e-government requires an appropriate information and communication technology (ICT) infrastructure, and usually, the government must own, manage and maintain such technology systems and infrastructure. This can be very expensive. In addition, investments in systems and infrastructure need to be decided appropriately and wisely. However, this task is not simple because conventional IT infrastructure is rather rigid. If the system is too large, it will be used, resources will be wasted. But, if the system is too small, the upgrade is not simple [9].

\section{Methods}

Researchers used the Systematic Review (SR) approach as a research method by Kitchenham[10]. This review is also based on Arief [11] and Wahono [12], whose aim was to identify and analyze the relevant literature based on research questions. The SR process in the topic of cloud computing in e-Government services is illustrated in Figure 1. This guide will be applied to identify the benefits and risks of cloud computing in e-government.

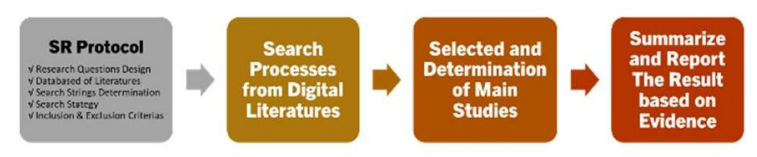

Fig. 1. The SR protocol in the field of Cloud Computing.

Fig 1, showed stages of the SR protocol according to the guidelines from Kitchenham [10]. There are 4 stages, namely thedisign of the SR protocol, Search Processes, Selected \& Determination of Papers and the last one, Summarize and Report the Result based on Evidence.

\subsection{Systematic Review Protocol}

Based on Figure 1, this paper specifies using SR protocol for this research as follows in Table 1:

Table 1. SR Protocols.

\begin{tabular}{|c|c|}
\hline $\begin{array}{c}\text { SR } \\
\text { Protocol } \\
\end{array}$ & Explanations \\
\hline $\begin{array}{l}\text { Research } \\
\text { Question }\end{array}$ & $\begin{array}{l}\text { RQ1: What are the benefits of cloud } \\
\text { computing in e-government Tasks? } \\
\text { RQ2: What are the risks of cloud computing } \\
\text { in e-government Tasks? }\end{array}$ \\
\hline $\begin{array}{c}\text { Motivation } \\
\text { Question }\end{array}$ & $\begin{array}{l}\text { MQ1: Identifying benefits of cloud computing } \\
\text { in e-government task } \\
\text { MQ2: Identifying risks of cloud computing in } \\
\text { e-government task }\end{array}$ \\
\hline $\begin{array}{l}\text { Sources } \\
\text { Searched }\end{array}$ & $\begin{array}{l}\text { Science Direct (www.sciencedirect.com) } \\
\text { Scopus (www.scopus.com) } \\
\text { IEEE Xplore (http:/ieeexplore.ieee.org) } \\
\text { Research Gate (https://www.researchgate.net) } \\
\text { Wiley Online Library (onlinelibrary.wiley.com) }\end{array}$ \\
\hline $\begin{array}{l}\text { Search } \\
\text { terms }\end{array}$ & $\begin{array}{l}\text { ("cloud" AND "computing" AND "benefit" } \\
\text { AND "risk" AND "e-government") }\end{array}$ \\
\hline
\end{tabular}

\begin{tabular}{|c|l|}
\hline $\begin{array}{c}\text { SR } \\
\text { Protocol }\end{array}$ & \multicolumn{1}{|c|}{ Explanations } \\
\hline Inclusions & $\begin{array}{l}\text { Year from 2015 to 2020 } \\
\text { Publication type "journals" or "conferences" }\end{array}$ \\
\hline Exclusion & Non-English \\
\hline \multirow{5}{*}{ Search } & $\begin{array}{l}\text { Step 1: Inserting the search string into search } \\
\text { features in the digital library website. } \\
\text { Step 2: Stating the total summary of searching } \\
\text { using the keywords that appear as "studies } \\
\text { found". } \\
\text { Step 3: Reading the title of the papers. When } \\
\text { the title is not clear for identifying the paper, } \\
\text { then the abstract will be explored. Then the } \\
\text { paper will be downloaded and categorized as } \\
\text { 'selected studies.' } \\
\text { Step 4: The 'selected studies' will be studied } \\
\text { to see their relevance to the objectives of the } \\
\text { study. The relevant papers will be categorized } \\
\text { as 'main studies.' }\end{array}$ \\
\hline
\end{tabular}

\subsection{Literature Search Result}

In this paper, we extracted data from a total of 110 potential publications. The paper using a Systematic review conducted on papers that meet the date range from 2015 to 2020 related to the topic of cloud computing in e-government. Figure 2 illustrates the search process.

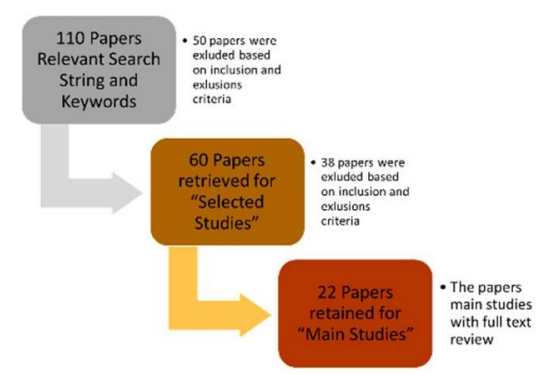

Fig. 2. The SR search result.

Meanwhile, cloud computing emerged and a paradigm shift in implementation in the IT/IS field [13]. Figure 3 shows the distribution of cloud computing publications published by year. Data collection was limited to publications from 2015 to 2020 with 20 research papers collected and analyzed. Figure 3 illustrates the progress of the number of publications from 2015, then there was a downward trend in 2017.

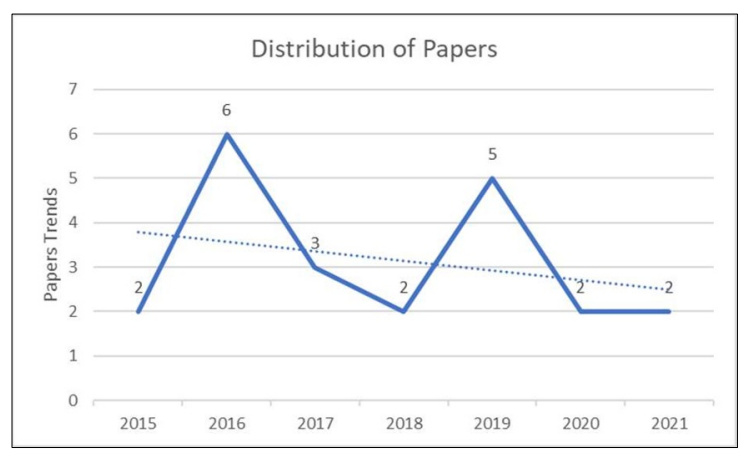

Fig. 3. The Papers Count Trends.

Fig. 3 showed the trend of distribution of papers on the topic of cloud computing in e-government over the last 
5-6 years. From the graph Fig. 3 it can be seen that there is an upward trend in 2016 and 2019, and a downward trend in 2017-2020.

\subsection{Selected Protocol}

Table 2 shows selected papers to be reviewed in this Systematic Review (SR) Protocol.

Table 2. Selected Papers based SR.

\begin{tabular}{|c|c|c|c|}
\hline No & Sources & Tittle & Year \\
\hline 1 & $\begin{array}{l}\text { Research } \\
\text { Gate }\end{array}$ & $\begin{array}{l}\text { Benefits and Issues of Cloud } \\
\text { Computing for E-Government } \\
\end{array}$ & 2015 \\
\hline 2 & $\begin{array}{l}\text { Science } \\
\text { Direct }\end{array}$ & $\begin{array}{c}\text { A Review on Cloud Data } \\
\text { Security and its Mitigation } \\
\text { Techniques [14] }\end{array}$ & 2015 \\
\hline 3 & $\begin{array}{l}\text { Science } \\
\text { Direct }\end{array}$ & $\begin{array}{c}\text { E-Governance Paradigm } \\
\text { Using } \\
\text { Cloud Infrastructure: Benefits } \\
\text { and Challenges[15] }\end{array}$ & 2016 \\
\hline 4 & $\begin{array}{l}\text { IEEE } \\
\text { Xplore }\end{array}$ & $\begin{array}{l}\text { Cloud computing security } \\
\text { issues: An analysis [16] }\end{array}$ & 2016 \\
\hline 5 & $\begin{array}{l}\text { IEEE } \\
\text { Xplore }\end{array}$ & $\begin{array}{l}\text { Security risk factors that } \\
\text { influence cloud computing } \\
\text { adoption in Saudi Arabia } \\
\text { government agencies [5] }\end{array}$ & 2016 \\
\hline 6 & $\begin{array}{l}\text { Wiley } \\
\text { Online } \\
\text { Library }\end{array}$ & $\begin{array}{l}\text { Analysis of the Determinants } \\
\text { of Software-as-a-Service } \\
\text { Adoption in Small Businesses: } \\
\text { Risks, Benefits, and } \\
\text { Organizational and } \\
\text { Environmental Factors [17] }\end{array}$ & 2016 \\
\hline 7 & $\begin{array}{l}\text { Research } \\
\text { Gate }\end{array}$ & $\begin{array}{c}\text { Cloud Computing Benefits } \\
{[18]}\end{array}$ & 2016 \\
\hline 8 & $\begin{array}{l}\text { Research } \\
\text { Gate }\end{array}$ & $\begin{array}{c}\text { Overview Of Cloud } \\
\text { Computing, Benefits And } \\
\text { Drawbacks [19] }\end{array}$ & 2016 \\
\hline 9 & $\begin{array}{l}\text { Research } \\
\text { Gate }\end{array}$ & $\begin{array}{l}\text { Public Cloud Computing; } \\
\text { Benefits and Risks to Users } \\
\text { and Potential Users [20] }\end{array}$ & 2016 \\
\hline 10 & $\begin{array}{l}\text { IEEE } \\
\text { Xplore }\end{array}$ & $\begin{array}{l}\text { Utilizing Cloud Computing in } \\
\text { public sector cases from the } \\
\text { world [4] }\end{array}$ & 2017 \\
\hline 11 & $\begin{array}{l}\text { Science } \\
\text { Direct }\end{array}$ & $\begin{array}{c}\text { A Comprehensive Survey on } \\
\text { Security in Cloud Computing } \\
{[21]}\end{array}$ & 2017 \\
\hline 12 & $\begin{array}{l}\text { Science } \\
\text { Direct }\end{array}$ & $\begin{array}{c}\text { A framework for critical } \\
\text { security factors that influence } \\
\text { the decision of cloud adoption } \\
\text { by Saudi government agencies } \\
{[22]}\end{array}$ & 2017 \\
\hline 13 & $\begin{array}{l}\text { Science } \\
\text { Direct }\end{array}$ & $\begin{array}{l}\text { A proposed hybrid model for } \\
\text { adopting cloud computing in } \\
\text { e-government [1] }\end{array}$ & 2018 \\
\hline 14 & $\begin{array}{l}\text { Research } \\
\text { Gate }\end{array}$ & $\begin{array}{l}\text { Analysis of Risks and Security } \\
\text { Requirements in Public Cloud } \\
{[23]}\end{array}$ & 2018 \\
\hline 15 & $\begin{array}{l}\text { Science } \\
\text { Direct }\end{array}$ & $\begin{array}{l}\text { A Proposed Hybrid Model For } \\
\text { Adopting Cloud Computing In } \\
\text { E-Government [1] }\end{array}$ & 2018 \\
\hline 16 & $\begin{array}{l}\text { IEEE } \\
\text { Xplore }\end{array}$ & $\begin{array}{l}\text { Determining Factors } \\
\text { Pertaining to Cloud Security } \\
\text { Adoption Framework in } \\
\text { Government Organizations: } \\
\text { An Exploratory Study [24] }\end{array}$ & 2019 \\
\hline
\end{tabular}

\begin{tabular}{|c|c|c|c|}
\hline No & Sources & Tittle & Year \\
\hline 17 & $\begin{array}{c}\text { IEEE } \\
\text { Xplore }\end{array}$ & $\begin{array}{c}\text { Hybrid Cloud Data Integration } \\
\text { Critical Success Factors: A } \\
\text { Case Study at PT Pos } \\
\text { Indonesia [25] }\end{array}$ & 2019 \\
\hline 18 & $\begin{array}{c}\text { Research } \\
\text { Gate }\end{array}$ & $\begin{array}{c}\text { Cloud Computing in } \\
\text { eGovernment: Benefits and } \\
\text { Challenges [2] }\end{array}$ & 2019 \\
\hline 19 & $\begin{array}{c}\text { Research } \\
\text { Gate }\end{array}$ & $\begin{array}{c}\text { The Application of Cloud } \\
\text { Computing in Government } \\
\text { Management [26] }\end{array}$ & 2020 \\
\hline 20 & Scopus & $\begin{array}{c}\text { Impact of public cloud } \\
\text { computing service in Korean } \\
\text { government organizations [27] }\end{array}$ & 2020 \\
\hline
\end{tabular}

\section{Results And Discussion}

The results direct answers to research questions based on SR protocol that the researcher generate from the data.

\subsection{What are the benefits of cloud computing for e-government Task?}

SR results show that cloud computing has many benefits for e-Government tasks. The results of cloud computing studies in the field of e-Government report a number of benefits. Some benefits are studied in depth, while others are mentioned superficially. Of the 22 papers, 14 papers mention the benefits of cloud computing or $70 \%$. Table 3 shows the benefits of cloud computing based on the SR process. Table 3. Benefits of Cloud Computing.

Table 3. Benefits of Cloud Computing in EGovernment.

\begin{tabular}{|c|c|}
\hline Benefits & References \\
\hline Cost Effective & $\begin{array}{c}\text { [1], [2], [3], [5], [7], [27], [25], } \\
{[18],[19],[20],[21]}\end{array}$ \\
\hline Data Centralization & {$[1],[19],[20]$} \\
\hline Easy Deployment & [5], [19] \\
\hline Increase Scalability & $\begin{array}{c}\text { [1], [2], [3], [4], [5], [7], [24], } \\
{[27],[18],[21],[22]}\end{array}$ \\
\hline Increase Flexibility & {$[2],[3],[4],[7],[19],[20]$} \\
\hline Simplicity & [3], [7], [19] \\
\hline Enhance Accessibility & [20] \\
\hline Green Computing & [1] \\
\hline Support Agility & [3] \\
\hline $\begin{array}{l}\text { Reliability and } \\
\text { Availability }\end{array}$ & [1], [3], [19], [20] \\
\hline Advanced Security & $\begin{array}{c}\text { [2], [5], [7], [24], [27], [25], } \\
{[18],[19],[22]}\end{array}$ \\
\hline Data Recovery & [1], [19] \\
\hline
\end{tabular}

Table 3. showed 12 benefits of cloud computing in egovernment task. 12 benefits hasil pencarian SR pada main studies yakni: Cost Effective, Data Centralization, Easy Deployment, Increase Scalabilit, Increase Flexibility, Simplicity, Enhance Accessibility, Green 
Computing, Support Agility, Reliability and Availability, Advanced Security, and Data Recovery.

\subsection{What are the risks of cloud computing?}

Obtained 22 papers, 18 papers mention the risk of cloud computing or $91 \%$. The SR results illustrate the risks of cloud computing in Table 4.

Table 4. The Risk of Cloud Computing in EGovernment.

\begin{tabular}{|l|l|}
\hline \multicolumn{1}{|c|}{ Risks } & \multicolumn{1}{c|}{ Reference } \\
\hline Performance & {$[1],[3],[7],[22],[17]$} \\
\hline Rules and Regulations & $\begin{array}{l}{[2],[5],[6],[16],[24],[25],} \\
{[20]}\end{array}$ \\
\hline Additional costs & {$[2],[19],[22],[17]$} \\
& \\
\hline Share Technology Risk & {$[5],[24],[26],[20]$} \\
\hline Vendor Lock-In & {$[23]$} \\
\hline Losing Control of Data & {$[1],[3],[7],[23],[16],[24]$} \\
\hline $\begin{array}{l}\text { Data Privacy and } \\
\text { Security }\end{array}$ & $\begin{array}{l}{[1],[2],[3],[4],[5],[6],[7],} \\
{[23],[16],[24],[25],[19],} \\
{[20],[14],[22],[17]}\end{array}$ \\
\hline Vulnerabilities & {$[1],[5],[23],[24],[19],[21]$} \\
\hline
\end{tabular}

Table 4. showed 8 risk of cloud computing in egovernment task. 8 risk hasil pencarian SR pada main studies yakni: Performance, Rules and Regulations, Additional costs, Share Technology Risk, Vendor Lock-In, Losing Control of Data, Data Privacy and Security, Vulnerabilities.

\subsection{Discussion of the Result of SR}

This section, the SR findings from our analytical efforts are summarized and discussed, focusing on the benefits and risks of cloud computing in e-government tasks.

\subsubsection{Benefits of Cloud Computing}

The SR results identify 12 benefits namely costeffectiveness, increased scalability, and advanced security which are mentioned more frequently in some literatures. Therefore, we will explore these benefits further as follows.

1. More Advanced Security: Public organizations with a centralized system rather than a silo structure can indicate a level of security [2]. Cloud providers can provide customers with centralized security as service patches and updates, which is more efficient than traditional organizational security capabilities [5].

2. More cost Effective: Cloud technology architecture reduces and eliminates capital expenditures and reduces existing operating costs[1]. Cost reduction due to capital expenditure is converted into operating costs of unit expenditures [7]. Cloud computing equipment is cost-effective because it does not require a lot of money to set up[20].

3. Increased Scalability: The cloud technology has scalability and can be used for a wide variety of applications. The data can be large without disturbing its performance [1]. Allows servers and storage devices to be used together and utilization is increased or decreased as needed [7]. Scalability is one of the main benefits of cloud computing because scalable solutions are implemented quickly and resources can be used whenever needed, increasing efficiency, saving time and saving costs [19].

4. Increase Flexibility: Akses lebih mudah dari perangkat internet yang sesuai, karena infrastruktur berada di luar lokasi dan disediakan oleh pihak ketiga dan diakses melalui internet, pengguna dapat terhubung dari mana saja, kapan saja dan lingkungan mana saja[7] [20].

5. More Simplicity: It is easy to use and set up. Customers don't have to worry about resource management and other stresses that come with setting up and managing infrastructure [20].

6. Easy deployment: The cloud provides the advantage of fast deployment. This type of functionality can help make system start-up easy[20].

7. Support agility: Agility is the ability to quickly and effectively respond to changing environment such as a more rapid response to citizens' needs in the short term, performing strategic adaptation (adapt to trends and issues) in the medium term, and long term shaping [3].

8. Reliability \& Availability: Network and data access are guaranteed to be maintained reliably because service providers are experts in maintaining infrastructure [20].

9. Data Centralization: Adopting the cloud for government agencies can create a central data set of shared resources, software, and infrastructure [1].

10. Data Recovery: The cloud offers tools and technologies that make disaster recovery simple and easy [1]. Data recovery when the hard drive crashes, which may cost a lot of money and waste time but will not be a problem with cloud usage[20].

11. Enhance accessibility: Cloud technology allows employees of multinational companies to get access to the information they need at any time no matter their geographic location [21].

12. Green Computing: One of the reasons for moving to cloud architecture is in governance. Instead of duplicating these facilities, with the cloud, one can offer a centralized infrastructure that can be used efficiently to minimize pollution from $\mathrm{CO} 2$ [1].

\subsubsection{Risks of Cloud Computing}

Data privacy and security issues are the most frequently mentioned risks. It was found that there were at least 8 identified risks which were further explored as follows.

1. Data Privacy and Security Issue: E-government contains sensitive data and information about users and businesses, therefore the security of sensitive data and data security is very important [1]. Security issues can occur on servers in the cloud, client machines, and networks [3]. The risk of security and 
privacy issues is a strategic and operational risk of the organization [7].

2. Share Technology Risk Issue: Infrastructure as a service is constructed on shared infrastructure that is frequently not considered to accommodate a multitenant architecture such as CPU caches and GPUs [5].

3. Vendor Lock-In Issue: As a user, there is a risk of going through a bothersome process, when migrating from one provider to another. The user has to decide on a SLA (Service Level Agreement), while accepting a cloud and categorizing Service Provider for using the Services [23].

4. Performance Issue: The performance issue, especially for data intensive computation as client machines are geographically distanced, which could be a thousand miles away from the cloud. Finally, internet speed will definitely affect the performance [1]. Issues of poor performance are common with new systems because the actual load is different from the predicted load [7].

5. Regulatory compliance is an effective factor that can prevent secure transfers to cloud computing. This risk stems from the fact that there are no government regulations or directives that can support companies in the event of a data breach [5]. This is a serious problem that can put organizations practicing cloud computing into trouble because, the rules and regulations regarding right and wrong information differ from country to country [21].

6. Additional Cost Issues: At first, cloud computing applications may seem a lot less expensive than certain self-installed and run software. But customers need to ensure that cloud applications have all the features that software should have, otherwise identifying missing features and updating them requires additional costs, high maintenance and operational costs [2][20].

7. Vulnerabilities Issue: Storing information in the cloud could make the companies vulnerable to external hack attacks and threats; therefore there is always the lurking possibility of theft of sensitive data [19].

8. Losing Control of Data Issue: The data is stored in the cloud; it will be placed in third party data centers where we have little control over the data and the cloud computing provider has complete access to the sensitive data [1]. Losing control over data can be a big problem as trust can be the key to cloud computing adoption by public organizations. Since data is stored in the cloud, can governments trust cloud providers to protect data at the same level as protection if data is stored locally? Trust cannot be built easily, especially if there is no third party who can guarantee the security and privacy of data or information stored in the cloud [3]. The organization's ownership rights to data must be clearly defined in the service contract to allow for a basis for trust and data privacy [7].

\section{Conclusions and Future Work}

This study aims to identify and analyze the benefits and risks of cloud computing in e-Government task. The study used a systematic review approach, collecting and analyzing 22 relevant research articles and discussing cloud computing in the e-government field. Based on the results of teh SR protocol there were 12 identified benefits of e-government task. Its benefits are cost Effective, Data Centralization, Easy Deployment, Increase Scalabilit, Increase Flexibility, Simplicity, Enhance Accessibility, Green Computing, Support Agility, Reliability and Availability, Advanced Security, and Data Recovery. The most common benefits are costeffectiveness, increased scalability and advanced security. Despite the many benefits found in leveraging cloud computing in e-government, there are still many risks that need to be anticipated. There are 8 identified risks of cloud computing such as Data Privacy and Security, Sharing Technology Risks, Vendor Lockout, Performance, Rules and Regulations, Additional Charges, Vulnerabilities, and Loss of Data Control. Among the 8 identified risks, risks related to data privacy and security are the most frequently mentioned in systematic reviews.

Future work of this research includes search string/keywords selection and source selection. Some of the benefits and risks may be better explained in the context of computer science, while remaining applicable to the e-Government field. Nevertheless, the researcher hopes that this review offers a useful overview of the use of cloud computing in e-Government tasks. Government Organizations should use the benefits to achieve successful cloud computing adoption and pay attention to the risks of cloud computing adoption. Further research can be done from the perspective of the quality of public services.

\section{References}

1. Ali, K.E.; Mazen, S.A.; Hassanein, E.E. ScienceDirect A proposed hybrid model for adopting cloud computing in e-government. Futur. Comput. Informatics J. (2018), 3, 286-295, doi:10.1016/j.fcij.2018.09.001.

2. Danielsen, F.; Ronzhyn, A. Cloud Computing in eGovernment : Benefits and Challenges. (2019).

3. Almunawar, M.N. Benefits and Issues of Cloud Computing for E-Government. Rev. Public Adm. Manag. (2015), 03, 1-2, doi:10.4172/2315$7844.1000 \mathrm{e} 105$.

4. Abu-shanab, E.; Estatiya, F. Utilizing Cloud Computing in Public Sector Cases from the World. (2017), 1702-1705.

5. Alassafi, M.O.; Alharthi, A.; Walters, R.J.; Wills, G.B. Security Risk factors that influence Cloud Computing Adoption in Saudi Arabia Government Agencies. (2016), 28-31.

6. Ali, O.; Shrestha, A.; Chatfield, A.; Murray, P. Assessing information security risks in the cloud: A case study of Australian local government authorities. Gov. Inf. Q. (2020), 37, 101419 [1-20], doi:10.1016/j.giq.2019.101419. 
7. Jones, S.; Irani, Z.; Sivarajah, U.; Love, P.E.D. Risks and rewards of cloud computing in the UK public sector: A reflection on three Organizational case studies. Inf. Syst. Front. (2019), 21, 359-382, doi:10.1007/s10796-017-9756-0.

8. Suhanto, A. Hybrid Cloud Data Integration Critical Success Factors: A Case Study at PT Pos Indonesia.

9. Almunawar, M.N. Review of Public Administration and Management Benefits and Issues of Cloud Computing for E-Government. (2015), 3, 1-2, doi:10.4172/2315-7844.1000e105.

10. Kitchenham, B.; Brereton, P. A systematic review of systematic review process research in software engineering. Inf. Softw. Technol. (2013), 55, 20492075, doi:10.1016/j.infsof.2013.07.010.

11. Rahmatika, M.; Krismawati, D.; Rahmawati, S.D.S.D.; Arief, A.; Sensuse, D.I.D.I.; Dzulfikar, M.F.M.F. An open government data maturity model: A case study in BPS-statistics Indonesia. 2019 7th Int. Conf. Inf. Commun. Technol. ICoICT 2019 (2019),

$1-7$, doi:10.1109/ICoICT.2019.8835352.

12. Wahono, R.S. A Systematic Literature Review of Software Defect Prediction: Research Trends, Datasets, Methods and Frameworks. J. Softw. Eng. (2015), 1, 1-16.

13. Indriasari, E.; Prabowo, H.; Meyliana; Hidayanto, A.N. Key benefits, challenges, and risk ofcloud business intelligence: A systematic literature review. Int. J. Mech. Eng. Technol. (2018), 9, 819831.

14. Selvamani, K.; Jayanthi, S. A Review on Cloud Data Security and its Mitigation Techniques. Procedia - Procedia Comput. Sci. (2015), 48, 347352, doi:10.1016/j.procs.2015.04.192.

15. Dash, S.; Kumar, S. E-Governance Paradigm Using Cloud Infrastructure: Benefits and Challenges. Procedia - Procedia Comput. Sci. (2016), 85, 843-855, doi:10.1016/j.procs.2016.05.274.

16. Gandhi, K.G. and P. Cloud computing security issues: An analysis.; (2016); pp. 3858-3861.

17. Kim, H.; Jang, S.Y.; Yang, K.H. Analysis of the Determinants of Software-as-a-Service Adoption in Small Businesses: Risks, Benefits, and Organizational and Environmental Factors. (2017), doi: $10.1111 /$ jsbm.12304.

18. Ayob, S. Cloud Computing Benefits. (2016).

19. Nwogbaga, Nweso Emmanuel; Ogbaga, I.N. Overview of Cloud Computing, Benefits and Drawbacks. EPRA Int. J. Multidiscip. Res. (2016), 2.

20. Shrivas, M.K.; Singh, S.V.; Management, D. Public Cloud Computing; Benefits and Risks to Users and Potential Users PUBLIC CLOUD COMPUTING; (2016).

21. Ramachandra, G.; Iftikhar, M.; Khan, F.A. A Comprehensive Survey on Security in Cloud Computing. Procedia Comput. Sci. (2017), 110, 465-472, doi:10.1016/j.procs.2017.06.124.

22. Alassafi, M.O.; Alharthi, A.; Walters, R.J.; Wills, G.B. A Framework for Critical Security Factors that Influence the Decision of Cloud Adoption by Saudi Government Agencies. Telemat. Informatics (2017), doi:10.1016/j.tele.2017.04.010.

23. Banushri, A.; Karthika, R.A. Analysis of Risks and Security Requirements in Public Cloud. (2018), 7, 223-226.

24. Alassafi, M.O.; Alghamdi, R.; Alshdadi, A.; Abdulwahid, A. Al; Bakhsh, S.T. Determining Factors Pertaining to Cloud Security Adoption Framework in Government Organizations: An Exploratory Study. IEEE Access (2019), 7, 136822-136835, doi:10.1109/ACCESS.2019.2942424.

25. Suhanto, A.; Hidayanto, A.N.; Naisuty, M.; Bowo, W.A.; Ayuning Budi, N.F.; Phusavat, K. Hybrid Cloud Data Integration Critical Success Factors: A Case Study at PT Pos Indonesia. Proc. 2019 4th Int. Conf. Informatics Comput. ICIC 2019 (2019), doi:10.1109/ICIC47613.2019.8985748.

26. Zhang, $H$. The application of cloud computing in government management. IOP Conf. Ser. Mater. Sci. Eng. (2020), 750, doi:10.1088/1757899X/750/1/012166.

27. Ashihara, K. Impact of public cloud computing service in korean government organizations. (2020), 11 313-318, doi:10.24507/icicelb.11.03.313. 